\title{
A Green and Efficient Method for the Preparation of 3,4-Dihydropyrimidin-2(1H)-ones Using Quaternary Ammonium-Treated Clay in Water
}

\author{
Soheil Sayyahi, ${ }^{1}$ Sedigheh Jahanbakhshi, ${ }^{2}$ and Zahra Dehghani ${ }^{2}$ \\ ${ }^{1}$ Department of Chemistry, Mahshahr Branch, Islamic Azad University, Mahshahr 63519, Iran \\ ${ }^{2}$ Department of Chemistry, Omidieh Branch, Islamic Azad University, Omidieh 63731, Iran \\ Correspondence should be addressed to Soheil Sayyahi; sayyahi.soheil@gmail.com
}

Received 9 May 2013; Accepted 3 September 2013

Academic Editor: Carla Boga

Copyright (C) 2013 Soheil Sayyahi et al. This is an open access article distributed under the Creative Commons Attribution License, which permits unrestricted use, distribution, and reproduction in any medium, provided the original work is properly cited.

A variety of 3,4-dihydropyrimidin-2(1H)-ones derivatives were synthesized via three-component Biginelli reaction. The quaternary ammonium-treated clay-catalyzed process proved to be simple, efficient, and environmentally friendly.

\section{Introduction}

Clays, nanoparticles with layered structures and hydrophilic nature, are used as Brønsted and/or Lewis acids or as bases to catalyze various types of organic reactions [1]. Otherwise, hydrophobic modification of the clay intrasurface allows many organic guest molecules to be easily intercalated [2]. In the modification of clay by ion exchange, the interlayer accessible compensating cations can be exchanged with a wide variety of hydrated inorganic cations or organic cations including those of amines, quaternary ammonium salts, ionic liquid, oxonium, sulfonium, phosphonium, and more complex cationic species such as methylene blue and cationic dyestuffs [3].

Multicomponent reactions (MCRs) are broadly defined as "one-pot" processes that combine three or more substrates either simultaneously or through a sequential-addition procedure that does not involve any change of solvent. By minimizing the number of synthetic operations while maximizing the buildup of structural and functional complexity, these highly step-economical reactions are particularly appealing in the context of target-oriented synthesis [4].

A literature survey showed that the Biginelli dihydropyrimidine synthesis as an MCR [5-7] attracts a high attention because of its ability for the preparation of compounds with potential biological and pharmaceutical properties. 3,4Dihydropyrimidin-2(1H)-ones derivatives (DHPMs) are one of these compounds which can be synthesized by cyclocondensation reaction of aldehyde, urea, and an easily enolizable carbonyl compound $[8,9]$.

Although various methods are reported for the synthesis of DHPMs, only few examples were developed with the aim of replacing conventional toxic and polluting Brønsted and Lewis acid catalysts with reusable solid acid heterogeneous catalysts, for the development of ecofriendly processes with reduced environmental impact [10-12].

Herein as part of our continued efforts to develop green and new catalysis systems with a reduced environmental impact [13-16], we decided to investigate the application of organophilic clay as a catalyst for synthesis of various 3,4dihydropyrimidin-2(1H)-ones in water.

\section{Results and Discussion}

Modification of clay by ion exchange makes hydrophilicity decrease and enhances the organophilicity in the interlayers of clay [17]. Therefore, treated clay may play an efficient role in the synthesis of DHPMs.

The catalyst was prepared by the cation exchange of $\mathrm{Na}^{+}$with cetyltrimethylammonium (CTAB) and characterized with FT-IR spectroscopy. In the spectrum of CTAB treated clay (Figure 1), $\mathrm{NCH}_{3}(\mathrm{C}-\mathrm{H})$ stretching vibration is observed at $3042 \mathrm{~cm}^{-1}$. Furthermore, the 2940 and $2850 \mathrm{~cm}^{-1}$ 
TABLE 1: Optimization of experimental conditions for synthesis of DHPMs.

\begin{tabular}{|c|c|c|c|c|}
\hline Entry & Catalyst & Temperature & Time (h) & Result \\
\hline 1 & CTAB-modified clay $(0.02 \mathrm{~g})$ & Reflux & 0.5 & Not completed, $44 \%$ yield \\
\hline 2 & CTAB-modified clay $(0.04 \mathrm{~g})$ & Reflux & 0.5 & Not completed, $77 \%$ yield \\
\hline 3 & CTAB-modified clay $(0.05 \mathrm{~g})$ & Reflux & 0.5 & Completed, $89 \%$ yield \\
\hline 4 & CTAB-modified clay $(0.05 \mathrm{~g})$ & r.t & 0.5 & Not completed, $35 \%$ yield \\
\hline 5 & Clay & Reflux & 0.5 & No reaction \\
\hline
\end{tabular}

Reaction conditions: benzaldehyde $(1 \mathrm{mmol})$, acetylacetone $(1 \mathrm{mmol})$, and urea $(1.5 \mathrm{mmol})$.

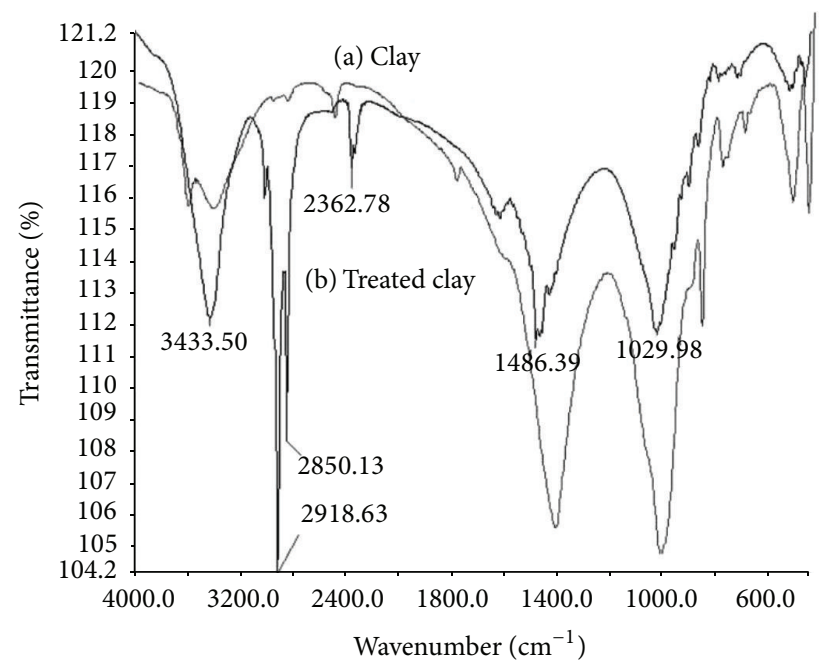

Figure 1: The FT-IR spectra of (a) clay, (b) treated clay.

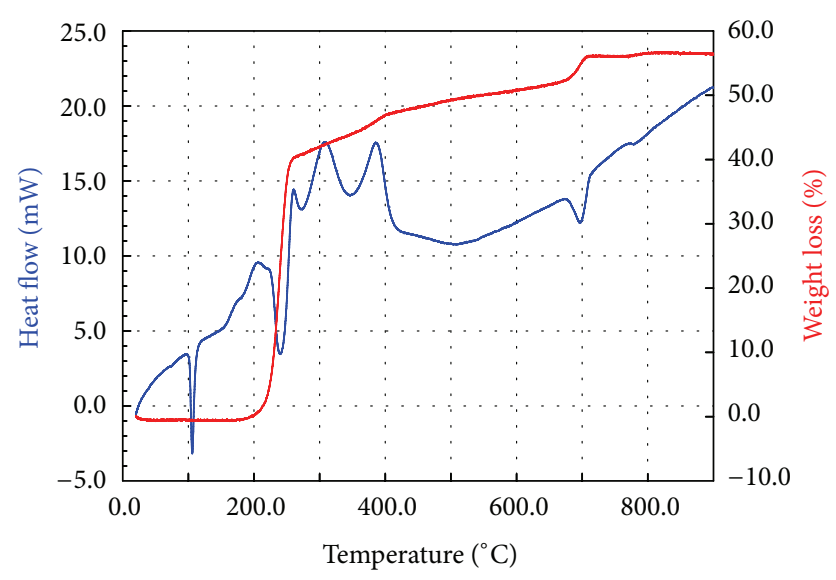

FIgURE 2: TGA curve of CTAB-modified clay.

peaks correspond to asymmetric and symmetric vibration of methylene group. This confirms the successful exchange of $\mathrm{CTAB}$ with sodium ions in the clay structure.

Also, the thermogravimetric analysis (TGA) of the organocatalyst was performed with a TGA/DSC simultaneous thermal analyzer apparatus, using a nitrogen atmosphere (Figure 2). TGA thermogram exhibits a $40 \%$ weight loss in the range of $220-240^{\circ} \mathrm{C}$ which is due to the breakdown of organic cations in the organocatalyst.
TABLE 2: Synthesis of 3,4-dihydropyrimidin-2(1H)-ones catalyzed by CTAB-modified clay.

\begin{tabular}{lcccc}
\hline Entry & $\mathrm{R}$ & $\mathrm{R}_{1}$ & Time $(\mathrm{h})$ & Yield (\%) $)^{\mathrm{a}, \mathrm{b}}$ \\
\hline $\mathbf{4 a}$ & $\mathrm{H}$ & $\mathrm{CH}_{3}$ & 0.5 & 89 \\
$\mathbf{4 b}$ & $4-\mathrm{NO}_{2}$ & $\mathrm{CH}_{3}$ & 0.75 & 91 \\
$\mathbf{4 c}$ & $3-\mathrm{NO}_{2}$ & $\mathrm{CH}_{3}$ & 1.0 & 92 \\
$\mathbf{4 d}$ & $4-\mathrm{OH}$ & $\mathrm{CH}_{3}$ & 0.75 & 87 \\
$\mathbf{4 e}$ & $2-\mathrm{MeO}$ & $\mathrm{CH}_{3}$ & 1.0 & 88 \\
$\mathbf{4 f}$ & $4-\mathrm{Cl}$ & $\mathrm{CH}_{3}$ & 0.5 & 85 \\
$\mathbf{4 g}$ & $2-\mathrm{Cl}$ & $\mathrm{CH}_{3}$ & 1.0 & 88 \\
$\mathbf{4 h}$ & $4-\mathrm{CH}_{3}$ & $\mathrm{CH}_{3}$ & 0.5 & 89 \\
$\mathbf{4 i}$ & $\mathrm{H}$ & $\mathrm{EtO}$ & 0.75 & 89 \\
$\mathbf{4 j}$ & $4-\mathrm{F}$ & $\mathrm{EtO}$ & 0.75 & 85 \\
$\mathbf{4 k}$ & $4-\mathrm{CH}$ & $\mathrm{EtO}$ & 0.5 & 90 \\
$\mathbf{4 l}$ & $4-\mathrm{MeO}_{3}$ & $\mathrm{EtO}$ & 0.75 & 87 \\
$\mathbf{4 m}$ & $4-\mathrm{Cl}$ & $\mathrm{EtO}$ & 0.5 & 90 \\
$\mathbf{4 n}$ & $2-\mathrm{Cl}$ & $\mathrm{EtO}$ & 0.75 & 86 \\
$\mathbf{4 o}$ & $4-\mathrm{NMe}$ & $\mathrm{EtO}$ & 0.75 & 84 \\
\hline
\end{tabular}

${ }^{a}$ Products are known and were identified by comparison of their physical and spectral data with those of authentic samples [18-22].

${ }^{\mathrm{b}}$ Isolated yields.

The optimization of the reaction conditions was carried out employing benzaldehyde as the substrate, and the best results were obtained by refluxing the mixture of $1 \mathrm{mmol}$ of aldehyde, $1 \mathrm{mmol}$ of acetylacetone, $1.5 \mathrm{mmol}$ of urea, and $0.5 \mathrm{~g}$ of catalyst in water (Table 1 ). To examine the scope and versatility of this method, the reaction was reinvestigated with various types of aryl-aldehyde bearing different electron-withdrawing and electron-donating substituents under the same reaction conditions (Scheme 1). In all cases, the desired 3,4-dihydropyrimidin-2(1H)-one has been produced in appropriate time and high yield (Table 2 ).

With the increasing interest in human health and environmental protection, more attention is being paid to green chemistry. With this view, we used benzaldehyde as a model and studied the recyclability and reusability of the catalyst. After completion of the reaction, the separated catalyst was washed with hot ethanol and dried (Figure 3). The catalyst was used for several subsequent cycles. To our surprise negligible depression in the performance of the catalyst was observed in the following cycles.

According to the obtained results, it is assumed that the reactants are brought together in among CTAB tails as 


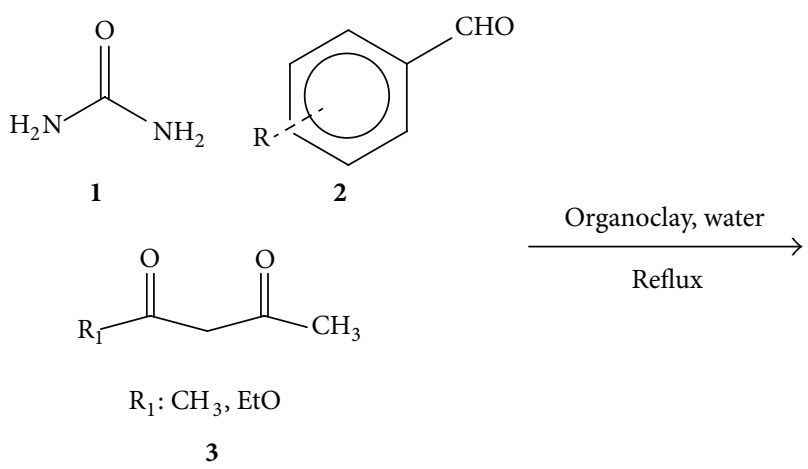<smiles>[R][X]c1cccc(C2NC(=O)NC(C)=C2C([R])=O)c1</smiles>

Scheme 1: Synthesis of DHPMs.

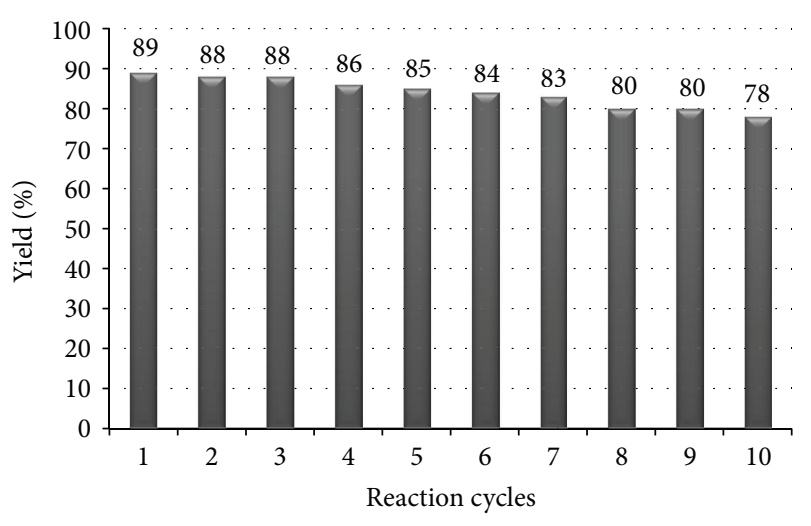

FIGURE 3: Reusability of catalyst.

organophilic regions and make a microvessel which accelerates the reaction (Figure 4).

\section{Experimental}

3.1. General Information. Natural $\mathrm{Na}^{+}$montmorillonite clay was provided from Khorasan Mines, Iran (XRF analysis: $\mathrm{SiO}_{2}=51.2 \%, \mathrm{Al}_{2} \mathrm{O}_{3}=10.7 \%$, and $\left.\mathrm{CaO}=12.8\right)$, and was ground, sieved (200-mesh), washed with water, and dried in $80^{\circ} \mathrm{C}$ for $2 \mathrm{~h}$ before using. All chemicals were purchased from commercial suppliers. The purity determination of the products and reaction monitoring were accomplished by TLC on polygram SILG/UV 254 plates. IR spectra were recorded on Bomem MB-Series 1998 FT-IR spectrometer. ${ }^{1} \mathrm{H}$ NMR and ${ }^{13} \mathrm{C}$ NMR spectra were taken on a $400 \mathrm{MHz}$ Bruker spectrometer.

3.2. General Procedures for the Preparation of Organoclay. Cetyltrimethylammonium bromide $(1.5 \mathrm{mmol}, 0.546 \mathrm{~g})$ was dissolved in $100 \mathrm{~mL}$ of $0.01 \mathrm{M} \mathrm{HCl}$ solution and stirred at $80^{\circ} \mathrm{C}$ until a clear solution was obtained. Then, montmorolite $(1.0 \mathrm{~g})$ was added to salt solution, and vigorous stirring was continued for another $6.0 \mathrm{~h}$. The precipitate formed was recovered by filtration and dispersed in hot water by mechanical stirring for $1 \mathrm{~h}$. The later process was repeated twice to get chloride-free organoclay. The final precipitate was thoroughly dried in an oven at $60^{\circ} \mathrm{C}$ for $24 \mathrm{~h}$ to obtain the CTAB-modified organoclay.

3.3. General Procedures for the Preparation of 3,4-Dihydropyrimidin-2(1H)-Ones. A mixture of aromatic aldehyde $(1 \mathrm{mmol})$, acetylacetone or ethyl acetoacetate $(1 \mathrm{mmol})$, urea $(1.5 \mathrm{mmol})$, and $0.5 \mathrm{~g}$ organoclay in $5 \mathrm{~mL}$ water was stirred under reflux condition for appropriate time (Table 1). After completion of the reaction that was monitored by TLC, the reaction mixture was cooled. The obtained was washed with water $(3 \times 10)$, dissolved in hot ethanol, and filtered to remove the catalyst. The combined filtrates were evaporated under reduced pressure to dryness to give, desired product. The solid crude products were recrystallized from ethanol.

5-Acetyl-6-methyl-4-phenyl-3,4-dihydropyrimidin-2(1H)-one 4a. m.p. $233-235^{\circ} \mathrm{C},{ }^{1} \mathrm{H}$ NMR (DMSO-d6, $400 \mathrm{MHz}$ ): $\delta=2.10(\mathrm{~s}, 3 \mathrm{H}), 2.28(\mathrm{~s}, 3 \mathrm{H}), 5.25(\mathrm{~s}, 1 \mathrm{H}), 7.35-7.23(\mathrm{~m}, 5 \mathrm{H})$, $7.83(\mathrm{~s}, 1 \mathrm{H})$, and $9.19(\mathrm{~s}, 1 \mathrm{H})$.

5-Acetyl-6-methyl-4-(4-nitrophenyl)-3,4-dihydropyrimidin-2 (1H)-one 4b. m.p. $230-232^{\circ} \mathrm{C},{ }^{1} \mathrm{H}$ NMR (DMSO-d6, $400 \mathrm{MHz}): \delta=2.18(\mathrm{~s}, 3 \mathrm{H}), 2.31(\mathrm{~s}, 3 \mathrm{H}), 5.38(\mathrm{~d}, 1 \mathrm{H}), 7.49(\mathrm{~d}$, $2 \mathrm{H}), 7.92(\mathrm{~d}, 2 \mathrm{H}), 8.2(\mathrm{~s}, 1 \mathrm{H})$, and $9.33 \mathrm{ppm}(\mathrm{s}, 1 \mathrm{H})$.

5-Acetyl-6-methyl-4-(3-nitrophenyl)-3,4-dihydropyrimidin-2 (1H)-one 4c. m.p. $222-225^{\circ} \mathrm{C},{ }^{1} \mathrm{H}$ NMR (DMSO-d6, $400 \mathrm{MHz}): \delta=2.05(\mathrm{~s}, 3 \mathrm{H}), 2.33(\mathrm{~s}, 3 \mathrm{H}), 5.67(\mathrm{~s}, 1 \mathrm{H})$, 7.45-7.27 (m, 4H), $7.72(\mathrm{~s}, 1 \mathrm{H})$, and $9.26(\mathrm{~s}, 1 \mathrm{H})$.

5-Acetyl-6-methyl-4-(4-hydroxyphenyl)-3,4-dihydropyrimidin-2(1H)-one 4d. m.p. 231-234 ${ }^{\circ} \mathrm{C},{ }^{1} \mathrm{H}$ NMR (DMSO-d6, $400 \mathrm{MHz}): \delta=2.10(\mathrm{~s}, 3 \mathrm{H}), 2.22(\mathrm{~s}, 3 \mathrm{H}), 5.04(\mathrm{~s}, 1 \mathrm{H}), 6.69(\mathrm{~d}$, $2 \mathrm{H}), 7.04(\mathrm{~d}, 2 \mathrm{H}), 7.60(\mathrm{~s}, 1 \mathrm{H}), 9.09(\mathrm{~s}, 1 \mathrm{H})$, and $9.31(\mathrm{~s}, 1 \mathrm{H})$.

5-Acetyl-6-methyl-4-(2-methoxyphenyl)-3,4-dihydropyrimidin-2(1H)-one $4 \boldsymbol{e}$. m.p. $248-250^{\circ} \mathrm{C},{ }^{1} \mathrm{H}$ NMR (DMSO-d6, $400 \mathrm{MHz}): \delta=2.02(\mathrm{~s}, 3 \mathrm{H}), 2.29(\mathrm{~s}, 3 \mathrm{H}), 3.82(\mathrm{~s}, 3 \mathrm{H}), 5.57(\mathrm{~d}$, $1 \mathrm{H}), 6.89(\mathrm{t}, 1 \mathrm{H}), 7.05-7.00(\mathrm{~m}, 2 \mathrm{H}), 7.36(\mathrm{br} \mathrm{s}, 1 \mathrm{H})$, and 9.14 (br s, $1 \mathrm{H}$ ). 


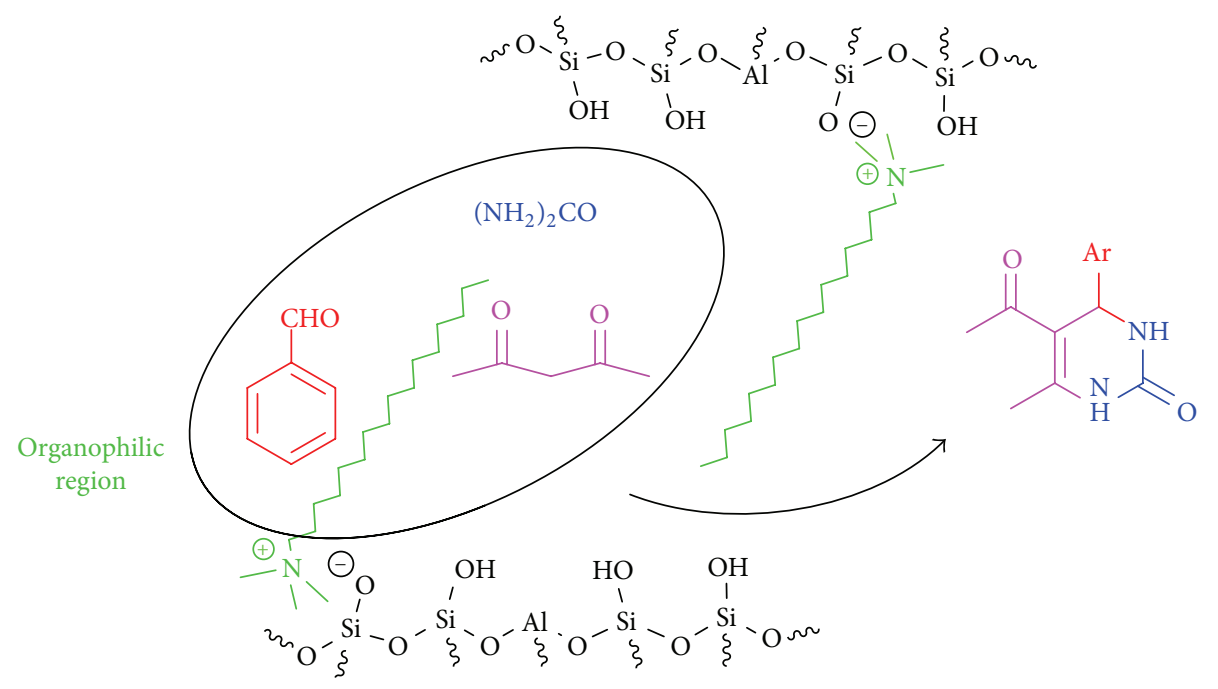

FIGURE 4: Schematic illustration of the reaction.

5-Acetyl-6-methyl-4-(4-chlorophenyl)-3,4-dihydropyrimidin2(1H)-one 4f. m.p. 204-206 ${ }^{\circ}$, ${ }^{1} \mathrm{H}$ NMR (DMSO-d6, $400 \mathrm{MHz}): \delta=2.14(\mathrm{~s}, 3 \mathrm{H}), 2.28(\mathrm{~s}, 3 \mathrm{H}), 5.25(\mathrm{~d}, 1 \mathrm{H}), 7.26(\mathrm{~d}$, $2 \mathrm{H}), 7.39(\mathrm{~d}, 2 \mathrm{H}), 7.85(\mathrm{~s}, 1 \mathrm{H})$, and $9.22 \mathrm{ppm}(\mathrm{s}, 1 \mathrm{H})$.

5-Acetyl-6-methyl-4-(2-chlorophenyl)-3,4-dihydropyrimidin2(1H)-one 4g. m.p. $228-229^{\circ} \mathrm{C},{ }^{1} \mathrm{H}$ NMR (DMSO-d6, $400 \mathrm{MHz}): \delta=2.05$ (s, 3H), 2.33 (s, 3H), 5.67 (s, 1H), 7.27$7.45(\mathrm{~m}, 4 \mathrm{H}), 7.72(\mathrm{~s}, 1 \mathrm{H})$, and $9.26(\mathrm{~s}, 1 \mathrm{H})$.

5-Acetyl-6-methyl-4-(4-methylphenyl)-3,4-dihydropyrimidin2(1H)-one 4h. m.p. 203-205 ${ }^{\circ}$, ${ }^{1} \mathrm{H}$ NMR (DMSO-d6, $400 \mathrm{MHz}): \delta=2.08(\mathrm{~s}, 3 \mathrm{H}), 2.26(\mathrm{~s}, 3 \mathrm{H}), 2.27(\mathrm{~s}, 3 \mathrm{H}), 5.21(\mathrm{~d}$, $1 \mathrm{H}), 7.13(\mathrm{~s}, 4 \mathrm{H}), 7.76(\mathrm{~s}, 1 \mathrm{H})$, and $9.13 \mathrm{ppm}(\mathrm{s}, 1 \mathrm{H})$.

5-Ethoxycarbonyl-4-phenyl-6-methyl-3,4-dihydropyrimidin2(1H)-one 4i. 201-203 ${ }^{\circ}{ }^{1}{ }^{1} \mathrm{H}$ NMR (DMSO-d6, $400 \mathrm{MHz}$ ): $\delta=1.09(\mathrm{t}, 3 \mathrm{H}), 2.25(\mathrm{~s}, 3 \mathrm{H}), 3.98(\mathrm{q}, 2 \mathrm{H}), 5.15(\mathrm{~d}, 1 \mathrm{H}), 7.23-$ 7.25 (m, 3H), 7.30-7.34 (m, 2H), 7.76 (br s, $1 \mathrm{H})$, and 922 (br s, $1 \mathrm{H})$.

5-Ethoxycarbonyl-4-(4-folorophenyl)-6-methyl-3,4-dihydropyrimidin-2(1H)-one 4j. m.p. 183-185 ${ }^{\circ} \mathrm{C},{ }^{1} \mathrm{H}$ NMR (DMSO-d6, $400 \mathrm{MHz}): \delta=1.05-1.10(\mathrm{t}, 3 \mathrm{H}), 2.25(\mathrm{~s}, 3 \mathrm{H}), 3.95-4.00(\mathrm{q}$, $2 \mathrm{H}), 5.14(\mathrm{~s}, 1 \mathrm{H}), 7.12-7.28(\mathrm{~m}, 4 \mathrm{H}), 7.76(\mathrm{~s}, 1 \mathrm{H})$, and $9.23(\mathrm{~s}$, $1 \mathrm{H})$.

5-Ethoxycarbonyl-4-(4-methylphenyl)-6-methyl-3,4-dihydropyrimidin-2(1H)-one $\mathbf{4 k}$. m.p. $170-173^{\circ} \mathrm{C},{ }^{1} \mathrm{H}$ NMR (DMSO$d 6,400 \mathrm{MHz}): \delta=1.04-1.12(\mathrm{t}, 3 \mathrm{H}), 2.23(\mathrm{~s}, 3 \mathrm{H}), 2.26(\mathrm{~s}$, $3 \mathrm{H}), 3.95-4.00(\mathrm{q}, 2 \mathrm{H}), 5.10(\mathrm{~s}, 1 \mathrm{H}), 7.12(\mathrm{~s}, 4 \mathrm{H}), 7.70(\mathrm{~s}, 1 \mathrm{H})$, and $9.17(\mathrm{~s}, 1 \mathrm{H})$.

5-Ethoxycarbonyl-4-(4-methoxyphenyl)-6-methyl-3,4-dihydropyrimidin-2(1H)-one $4 l$. m.p. $199-200^{\circ} \mathrm{C},{ }^{1} \mathrm{H}$ NMR (DMSO$d 6,400 \mathrm{MHz}): \delta=1.10(\mathrm{t}, 3 \mathrm{H}), 2.24(\mathrm{~s}, 3 \mathrm{H}), 372(\mathrm{~s}, 3 \mathrm{H}), 3.98$ (q, 2H), 5.09 (d, 1H), 6.88 (d, 2H), 7.15 (d, 2H), 7.69 (br s, 1H), and 9.17 (br s, $1 \mathrm{H})$.
5-Ethoxycarbonyl-4-(4-cholorophenyl)-6-methyl-3,4-dihydropyrimidin-2(1H)-one $4 m$. m.p. $208-210^{\circ} \mathrm{C},{ }^{1} \mathrm{H}$ NMR (DMSOd6, $400 \mathrm{MHz}): \delta=1.10(\mathrm{t}, 3 \mathrm{H}), 2.26(\mathrm{~s}, 3 \mathrm{H}), 3.98(\mathrm{q}, 2 \mathrm{H})$, $5.15(\mathrm{~s}, 1 \mathrm{H}), 7.26(\mathrm{~d}, 2 \mathrm{H}), 7.40(\mathrm{~d}, 2 \mathrm{H}), 7.80$ (br s, $1 \mathrm{H})$, and 9.27 (s, $1 \mathrm{H})$.

5-Ethoxycarbonyl-4-(2-cholorophenyl)-6-methyl-3,4-dihydropyrimidin-2(1H)-one 4 n. m.p. $222-224^{\circ} \mathrm{C},{ }^{1} \mathrm{H}$ NMR (DMSO$d 6,400 \mathrm{MHz}): \delta=0.99(\mathrm{t}, 3 \mathrm{H}), 2.30(\mathrm{~s}, 3 \mathrm{H}), 372(\mathrm{~s}, 3 \mathrm{H}), 3.89$ (q, 2H), $5.63(\mathrm{~d}, 1 \mathrm{H}), 7.25-7.32(\mathrm{~m}, 3 \mathrm{H}), 7.41(\mathrm{~d}, 1 \mathrm{H}), 7.73$ (br s, $1 \mathrm{H})$, and 9.30 (br s, $1 \mathrm{H})$.

5-Ethoxycarbonyl-4-(4-dimethylaminophenyl)-6-methyl-3,4dihydropyrimidin-2(1H)-one 4o. m.p. $254-256^{\circ} \mathrm{C},{ }^{1} \mathrm{H}$ NMR (DMSO-d6, $400 \mathrm{MHz}): \delta=1.11(\mathrm{t}, 3 \mathrm{H}), 2.23(\mathrm{~s}, 3 \mathrm{H}), 2.86(\mathrm{~s}$, $6 \mathrm{H}), 3.95(\mathrm{q}, 2 \mathrm{H}), 5.04(\mathrm{~s}, 1 \mathrm{H}), 6.64(\mathrm{~d}, 2 \mathrm{H}), 7.02(\mathrm{~d}, 2 \mathrm{H}), 7.60$ $(\mathrm{s}, 1 \mathrm{H})$, and $9.10(\mathrm{~s}, 1 \mathrm{H})$.

\section{Conclusion}

In conclusion, we have reported here the use of CTABmodified clay as an efficient catalyst in the synthesis of 3,4dihydropyrimidin-2(1H)-ones in water. This environmentally benign protocol offers several advantages such as a green and cost-effective procedure, short reaction time, easy workup, recovery, and reusability of heterogeneous catalyst and high yield of the products.

\section{Acknowledgment}

The authors are grateful to the Islamic Azad University, Mahshahr Branch, for support of this work.

\section{References}

[1] G. Nagendrappa, "Organic synthesis using clay and claysupported catalysts," Applied Clay Science, vol. 53, no. 2, pp. 106138, 2011. 
[2] H. He, J. Duchet, J. Galy, and J. F. Gerard, "Grafting of swelling clay materials with 3-aminopropyltriethoxysilane," Journal of Colloid and Interface Science, vol. 288, no. 1, pp. 171-176, 2005.

[3] N. H. Kim, S. V. Malhotra, and M. Xanthos, "Modification of cationic nanoclays with ionic liquids," Microporous and Mesoporous Materials, vol. 96, no. 1-3, pp. 29-35, 2006.

[4] B. B. Touré and D. G. Hall, "Natural product synthesis using multicomponent reaction strategies," Chemical Reviews, vol. 109, no. 9, pp. 4439-4486, 2009.

[5] C. O. Kappe, "Recent advances in the Biginelli dihydropyrimidine synthesis. New tricks from an old dog," Accounts of Chemical Research, vol. 33, no. 12, pp. 879-888, 2000.

[6] M. A. Kolosov, V. D. Orlov, D. A. Beloborodov, and V. V. Dotsenko, "A chemical placebo: $\mathrm{NaCl}$ as an effective, cheapest, non-acidic and greener catalyst for Biginelli-type 3,4-dihydropyrimidin-2(1H)-ones (-thiones) synthesis," Molecular Diversity, vol. 13, no. 1, pp. 5-25, 2009.

[7] J. P. Wan and Y. Liu, "Synthesis of dihydropyrimidinones and thiones by multicomponent reactions: strategies beyond the classical Biginelli reaction," Synthesis, vol. 2010, no. 23, pp. 39433953, 2010.

[8] S. Suresh and J. S. Sandhu, "Past, present and future of the Biginelli reaction: a critical perspective," Arkivoc, vol. 2012, no. 1, pp. 66-133, 2012.

[9] D. Ding and C. G. Zhao, "Primary amine catalyzed Biginelli reaction for the enantioselective synthesis of 3,4-dihydropyrimidin-2(1H)-ones," European Journal of Organic Chemistry, no. 20, pp. 3802-3805, 2010.

[10] O. Rosati, M. Curini, F. Montanari, M. Nocchetti, and S. Genovese, " $\alpha$-zirconium sulfophenylphosphonate as a catalyst for the synthesis of 3,4-dihydropyrimidin-2(1H)-one derivatives under solvent free conditions," Catalysis Letters, vol. 141, no. 6, pp. 850-853, 2011.

[11] J. Mondal, T. Sen, and A. Bhaumik, “ $\mathrm{Fe}_{3} \mathrm{O}_{4} @$ @mesoporous SBA15: a robust and magnetically recoverable catalyst for one-pot synthesis of 3,4-dihydropyrimidin-2(1H)-ones via the Biginelli reaction," Dalton Transactions, vol. 41, no. 20, pp. 6173-6181, 2012.

[12] M. Kargar, R. Hekmatshoar, A. Mostashari, and Z. Hashemi, "Efficient and green synthesis of 3,4-dihydropyrimidin-2(1H)ones/thiones using imidazol-1-yl-acetic acid as a novel, reusable and water-soluble organocatalyst," Catalysis Communications, vol. 15, no. 1, pp. 123-126, 2011.

[13] A. R. Kiasat and S. Sayyahi, "Immobilization of $\beta$-cyclodextrin onto Dowex resin as a stationary microvessel and phase transfer catalyst," Catalysis Communications, vol. 11, no. 5, pp. 484-486, 2010.

[14] S. Sayyahi, S. Menati, and M. Karamipour, "Al-MCM-41: an efficient and recyclable heterogeneous catalyst for the synthesis of $\beta$-hydroxy thiocyanates in water," Journal of Chemistry, vol. 2013, Article ID 561649, 5 pages, 2013.

[15] S. Sayyahi and J. Saghanezhad, "An efficient method for synthesis of phenacyl derivatives under homogeneous phase transfer catalyst condition in aqueous media," Chinese Chemical Letters, vol. 22, no. 3, pp. 300-302, 2011.

[16] S. Sayyahi, H. M. Rezaee, F. S. Khalfabadi, and M. Gorjizadeh, "1,1' -Bis-methyl-3,3-methylenebisimidazolium dichloride as an efficient phase transfer catalyst for ring opening of epoxides using $\mathrm{SCN}^{-}$and $\mathrm{N}_{3}{ }^{-}$in water," Journal of Chemical Research, vol. 36, no. 7, pp. 396-397, 2012.
[17] S. Sonawane, P. Chaudhari, S. Ghodke et al., "Combined effect of ultrasound and nanoclay on adsorption of phenol," Ultrasonics Sonochemistry, vol. 15, no. 6, pp. 1033-1037, 2008.

[18] X. Jing, Z. Li, X. Pan, Y. Shi, and C. Yan, " $\mathrm{NaIO}_{4}$-catalyzed onepot synthesis of dihydropyrimidinones at room temperature under solvent-free conditions," Journal of the Iranian Chemical Society, vol. 6, no. 3, pp. 514-518, 2009.

[19] A. R. Hajipour and M. Seddighi, "Pyridinium-based brønsted acidic ionic liquid as a highly efficient catalyst for one-pot synthesis of dihydropyrimidinones," Synthetic Communications, vol. 42, no. 2, pp. 227-235, 2012.

[20] C. Ramalingan, S. J. Park, I. S. Lee, and Y. W. Kwak, "A piperidinium triflate catalyzed Biginelli reaction," Tetrahedron, vol. 66, no. 16, pp. 2987-2994, 2010.

[21] Z. N. Siddiqui, "Bis[(L)prolinato-N,O]Zn-water: a green catalytic system for the synthesis of 3,4-dihydropyrimidin-2(1H)ones via the Biginelli reaction," Comptes Rendus Chimie, vol. 16, no. 2, pp. 183-188, 2013.

[22] G. Aridoss and Y. T. Jeong, "A convenient one-pot Biginelli reaction catalyzed by $\mathrm{Y}(\mathrm{OAc})_{3}$ : an improved protocol for the synthesis of 3,4-dihydropyrimidin-2(1H)-ones and their sulfur analogues," Bulletin of the Korean Chemical Society, vol. 31, no. 4, pp. 863-868, 2010. 

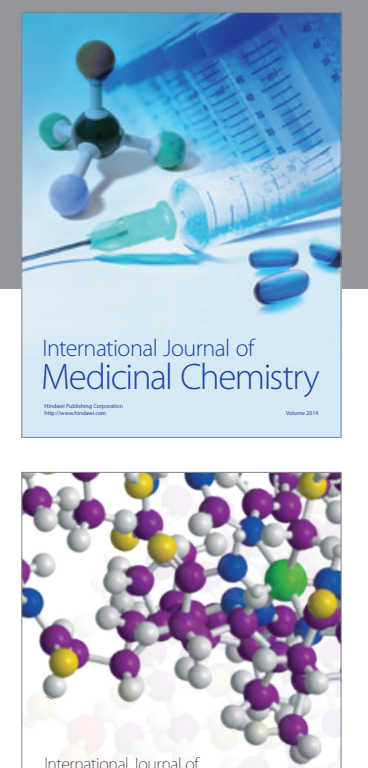

\section{Carbohydrate} Chemistry

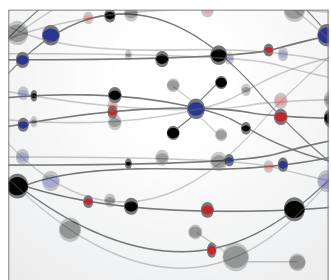

The Scientific World Journal
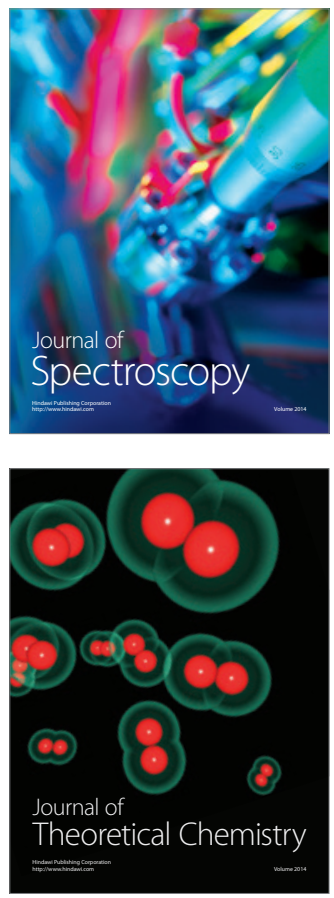
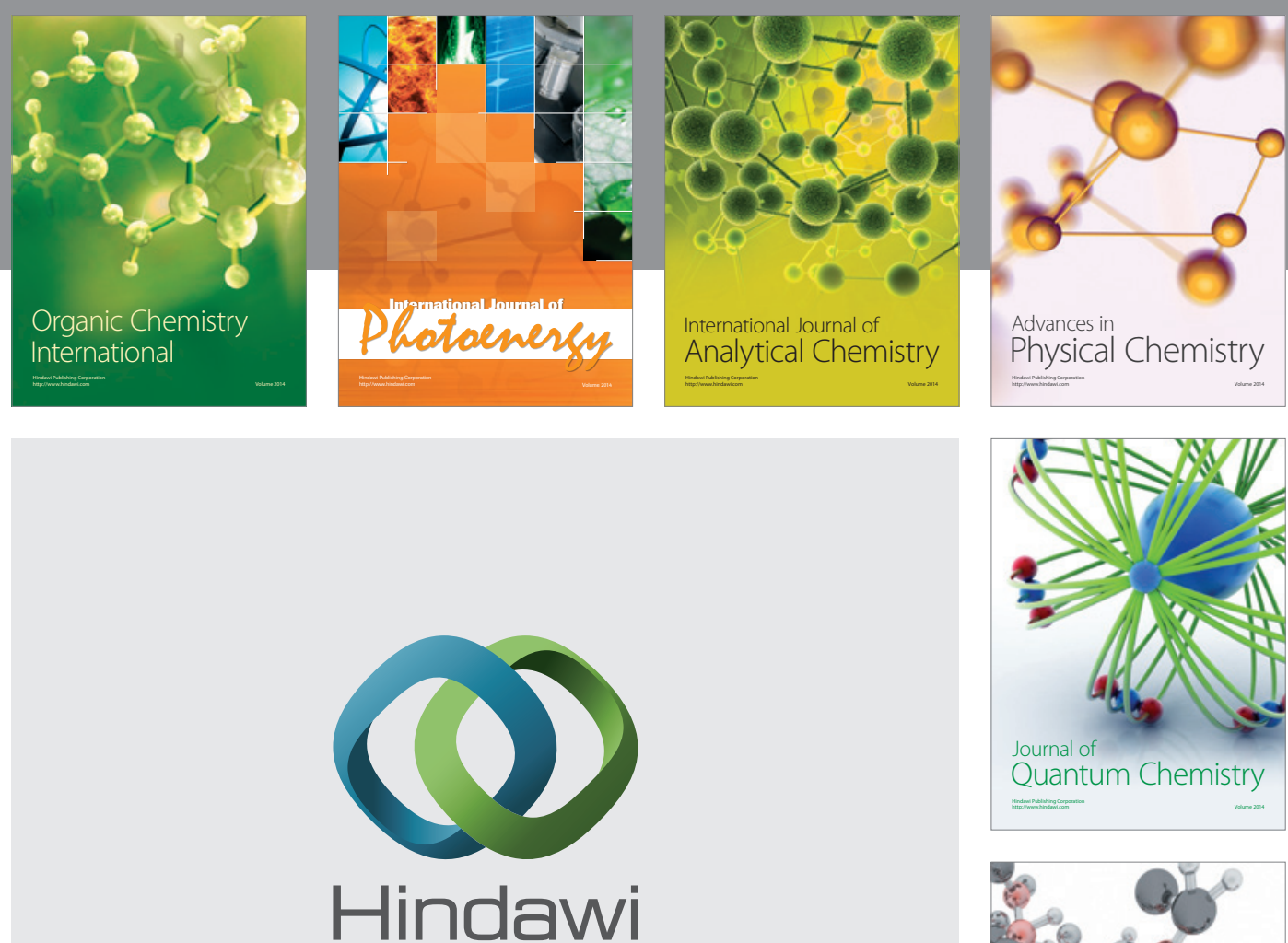

Submit your manuscripts at

http://www.hindawi.com

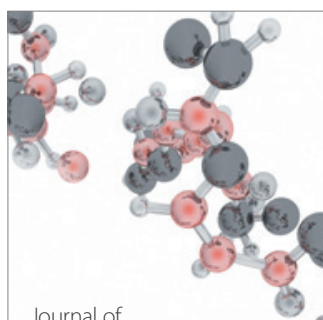

Analytical Methods

in Chemistry

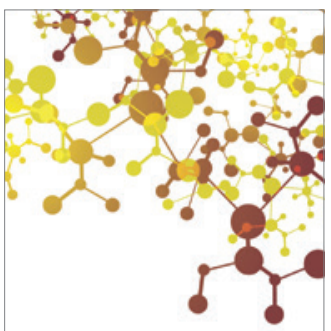

Journal of

Applied Chemistry

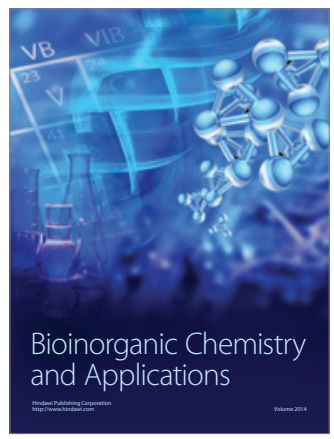

Inorganic Chemistry
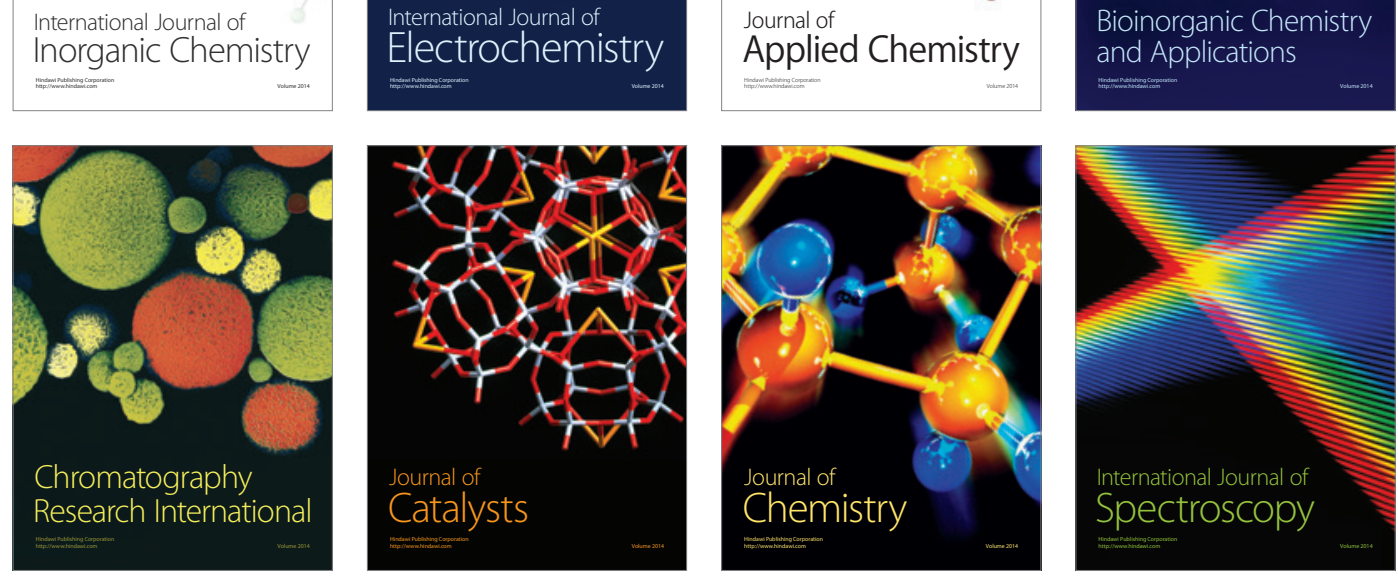